\title{
A Case Study in Applying the Learning Sciences to MOOC Design
}

\author{
Darcy G. Gordon ${ }^{1}$, Mary Ellen Wiltrout ${ }^{1^{*}}$ \\ ${ }^{1}$ MITx Biology, Massachusetts Institute of Technology, Department of Biology, Cambridge, \\ MA, USA \\ * Correspondence: \\ Mary Ellen Wiltrout \\ mew27@mit.edu
}

Keywords: learning sciences, online education, instructional design, digital learning, learning engineering, MOOC

\begin{abstract}
Evidence-based practices grounded in the learning sciences provide an opportunity for improved learning experiences in traditional in-person, as well as in hybrid and online environments. We advocate specifically that large-scale, online learning experiences can benefit from applications of the learning sciences. To that end, we participate in establishing a standard of practice in the development and design of Massive Open Online Courses (MOOCs). We present a description of how and why we use specific evidence-based learning science practices in a biochemistry MOOC with the intention to contribute to the discussion about the quality of online learning experiences, and lower the barrier for other practitioners seeking a scientific approach to course design. We believe that the application of evidence-based practices can make online learning experiences more rigorous and effective, and practitioners should optimize the use of these strategies through clever tests in specific contexts.
\end{abstract}

\section{Introduction}

The quality of learning experiences across the approximately 13,000 Massive Open Online Courses (MOOCs) offered since 2012 (Shah 2019) is heterogeneous. There are calls to assess the design of MOOCs, establish criteria for development, and standardize quality assurance measures (Alario-Hoyos, Pérez-Sanagustín, Cormier, et al. 2014; Alario-Hoyos, Pérez-Sanagustín, Kloos, et al. 2014; Doherty, Harbutt, and Sharma 2015; Kopp and Lackner 2014; Lee et al. 2016; Yousef et al. 2014). Best practices for teaching and learning rooted in the learning sciences advance scientific teaching methods through the adoption of active learning (Freeman et al. 2014; Handelsman et al. 2004), and promote efficient and effective ways to study (Miyatsu, Nguyen, and McDaniel 2018). Digital learning designers can and should translate many of these best practices to online learning environments. Our aim is to document this translation from the perspective of MOOC developers, by presenting a case study of applying evidence-based strategies in a biochemistry MOOC, and advocating for testing the effectiveness of instructional practices in specific online contexts.

As practitioners concerned with maximizing learning gains in an understudied, yet widely used non-traditional learning environment (Veletsianos and Shepherdson 2016), we are agnostic to adhering to strategies based in one conceptual framework of educational research over another. Digital learning designers should have all possible tools at their disposal for creating engaging and effective learning experiences. To this end, we take a systematic, eclectic, 
instructional design approach (Honebein and Sink 2012; Yanchar and Gabbitas 2011) to learning engineering, where we draw upon practices rooted in behaviorism, cognitivism, social learning, and constructivism, to address the challenges of online learning at scale.

Here we document practices supported by the learning sciences that we readily implement in an online learning environment to contribute to conversations in the community of practice about evidence-based approaches to MOOC design. We hope these conversations lower the barrier for other developers of online and hybrid experiences to apply these methods. We found the following practices both robust from a theoretical standpoint, and practical in terms of application in our course design. We outline the evidence-based practices applied to course assets organized by function (pre-instruction, multimedia content, formative assessment, supporting resources, and summative assessment). However it is worth noting that many of the practices overlap in their usage (Figure 1). This article is an exposition on why and how to use the learning sciences in a specific context as a model for others, while highlighting a few strategies, and not an exhaustive review of these practices.

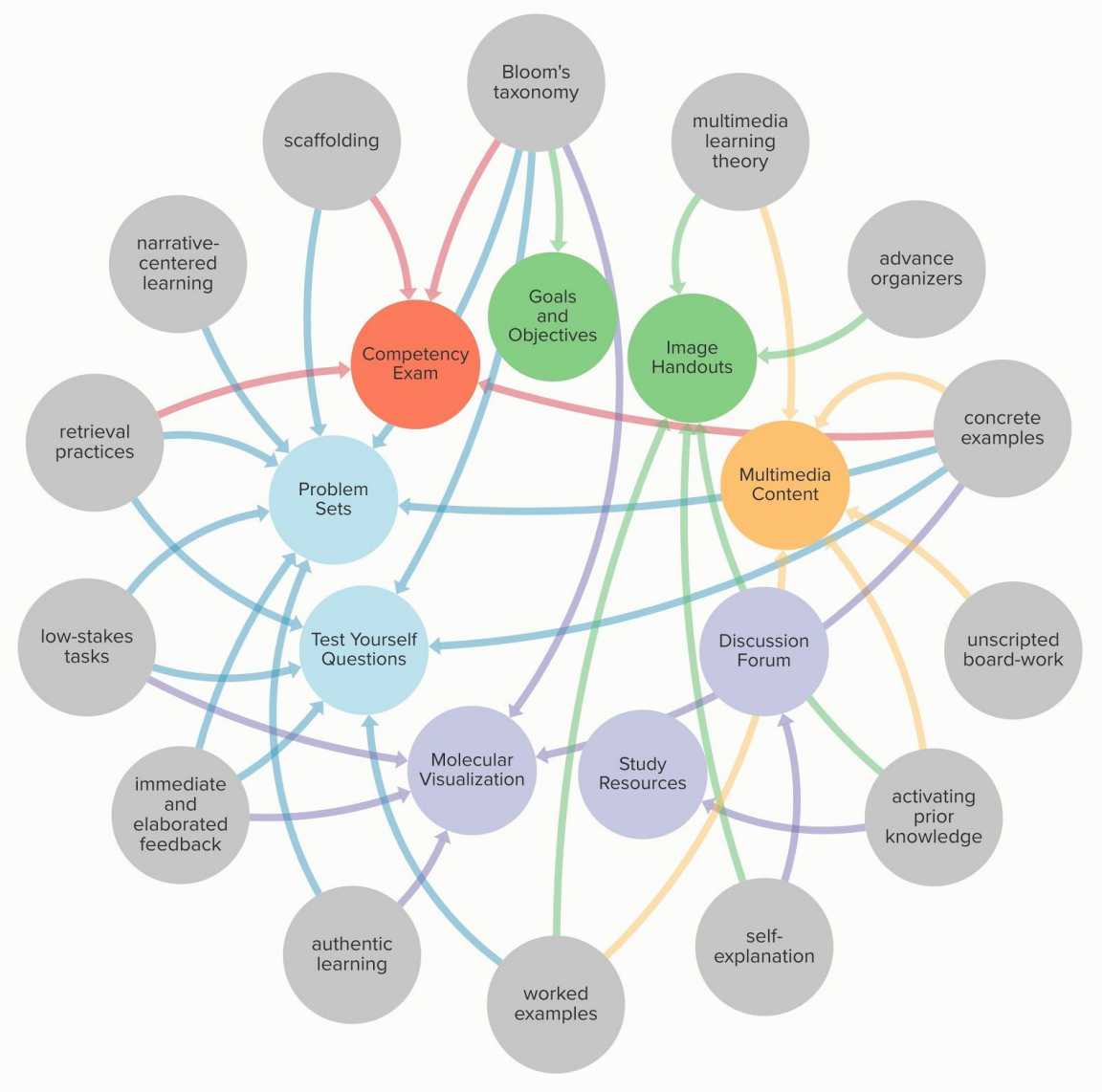

Figure 1. A mapping of evidence-based practices stemming from the learning sciences (gray outer nodes) to course assets (colorful inner nodes). The course assets are color-coded by function: green $=$ pre-instruction, yellow $=$ multimedia, purple $=$ supporting resources, blue $=$ formative assessments, and orange $=$ summative assessment. 


\section{Case Study Course Overview}

Our MOOC design case study started with the incorporation of hybrid approaches in a large enrollment, lecture-based biochemistry course taught at the Massachusetts Institute of Technology. Adapting from an Analysis, Design, Development, Implementation, and Evaluation (ADDIE) instructional systems design model (Peterson 2003; Lee et al. 2016), we iterated the design process over several semesters on campus, incorporating more evidence-based practices and expanding the resources offered before translating those learning experiences into a stand-alone MOOC available for worldwide distribution. The MOOC has a hierarchical structure comprised mainly of eight different topic units (like chapters in a book), each broken down into one or two learning sequences (analogous to sections of each chapter). The learning sequences contain a series of course assets (Figure 1, colorful nodes) designed to prime the learner for the material (pre-instructional strategies; Figure 1, green nodes), convey foundational information (multimedia content; Figure 1, yellow node), build understanding (formative assessments; Figure 1, blue nodes), and support learning (supporting resources; Figure 1, purple nodes). In addition to topic units and other supplemental material, the course ends with a comprehensive exam (summative assessment; Figure 1, orange node).

\section{Evidence-based Practices Employed}

Pre-instruction

To prime our MOOC learners for the introduction of new material in each learning sequence, we employ two pre-instructional techniques, learning objectives and advance organizers (Figure 1, green nodes). Positioned at the beginning of the learning sequences, we outline one or two big picture goals for each sequence as well as several measurable objectives the learner should meet by engaging with the sequence material. By outlining the goals and objectives that we used to develop and align the assessments during course development, we clearly communicate our expectations for the learner, and promote transparency in the course (Hartley and Davies 1976). We know from a survey of our hybrid learning experiences that students find these goals and objectives useful for studying, even when not explicitly directed to use them in this way. We also use a type of advance organizer (Hartley and Davies 1976; Bui and McDaniel 2015; Meng and Patty 1991; Weisberg 1970) in the form of image handouts. By presenting key images ahead of instruction, the learners have an opportunity to preview the material, have a scaffold on which to guide their note-taking, and make deeper connections during the video segments. These handouts contain a series of images that appear in the sequences, each coupled with an open-ended, yet focused question (Wylie and Chi 2014) designed to make connections between what each image represents and the learning sequence topic (Supplementary Image 1). We do not formally assess the coupled questions, but rather prompt self-explanation. Learners answer the questions in their own words, revealing their own thought process and understanding, which promotes metacognitive processes (Chi et al. 1994; Ainsworth and Th Loizou 2003; Aleven and Koedinger 2002).

\section{Multimedia Content}

To connect learners' prior knowledge to more advanced concepts in biochemistry, we offer a series of video and images, which we designed to maximize engagement and minimize extraneous cognitive load (Sweller 2005; 1994; Sweller, van Merriënboer, and Paas 2019) 
(Figure 1, yellow node). We filmed a live classroom, where the professor writes on a chalkboard to discuss the material unscripted. Students may prefer the professor writing on a board over presenting slides because the method is more interactive, the pace of the presentation is more accessible, and the information is streamlined (Brandl, Schneid, and Armour 2015). There is also evidence that unscripted lectures may be more engaging to learners than scripted deliveries (Thornton, Riley, and Wiltrout 2017). This method of multimedia content delivery meets the principles of multimedia learning that promote generative processing (personalization, voice, and embodiment) as well as some that maintain essential processing (modality and segmenting) (Clark and Mayer 2016; Mayer 2017). Often embedded within the videos are brief animations of the dynamic, process-oriented concepts and complex structures overlaid on the active discussion in class (Supplementary Video 1). These animations are consistent in style and color to familiarize learners with the representation of specific concepts (pretraining) (Mayer, Mathias, and Wetzell 2002). We also took care to adhere to the remaining multimedia learning principles (coherence, signalling, redundancy, and contiguity) while maintaining scientific accuracy, to promote a deeper understanding of the core concepts represented and maintain a manageable cognitive load for learners (Sweller 2005; Mayer 2017; Clark and Mayer 2016).

\section{Formative Assessments}

We include over 600 formative assessments to guide learners through the process of constructing a foundational understanding of biochemistry and transferring that understanding to novel contexts (Figure 1, blue nodes). All the assessments are graded automatically, including multiple choice and dropdown menu responses, checkbox, and numerical and text inputs. To gauge understanding of the new material introduced in each video segment, we intersperse test yourself questions (TYs) between videos. We include concrete examples in TYs to help learners generalize abstract ideas and transfer knowledge to different contexts (Paivio, Walsh, and Bons 1994; Weinstein, Madan, and Sumeracki 2018). These concrete examples can also serve a dual purpose to personally connect the learner to the material. Our examples often have relevance to current research, medical applications, or everyday life, which can help promote intrinsic motivation to learn (Ambrose et al. 2010). One such example is a TY in the $\mathrm{pH}$ and buffers unit, where we ask learners to calculate the $\mathrm{pH}$ of a homemade buttermilk substitute given the volume of lemon juice and milk, the amount of citric acid in lemon juice, and the dissociation constant of citric acid. This question goes beyond a simple calculation and engages the learner in how biochemistry applies to daily living.

Engaging learners is a challenge for most formative assessments, so we constructed problem sets (PSs), at the end of every unit, to generate interest, as well as prompt learners to think deeply about what they learned and apply their knowledge to new contexts. We take inspiration from narrative-centered learning in gaming (Mott et al. 1999) to leverage the great appeal of storytelling in education. The PS questions are connected by an ongoing story about taking biochemistry and engaging in research as an undergraduate, where we inject the learners as characters in the narrative. The assessments that compose the PSs reference objectives covered throughout the associated learning sequence(s), and as such represent both spaced retrieval and interleaving practices (Roediger and Butler 2011; Karpicke and Roediger 2007; Birnbaum et al. 2013). Retrieval practices such as these, and the resulting testing effect, are useful techniques for studying and retaining information on longer timescales (Roediger and Karpicke 2006; Rowland 2014). The PS questions also contain scaffolding to break complex 
questions into component parts, offering opportunities for the learners to adapt their approaches based on the immediate feedback given (Reiser 2004). An example of scaffolding in the course is where we task the learners with a series of questions about a mathematical description of cooperative binding. First, we ask learners to identify the correct mathematical transformations of their raw data to set up the calculation. Then the learners need to select the correct mathematical expression to fit the data, and perform calculations to generate a model from the transformed data and mathematical expression selected earlier. Finally, learners must interpret the output of the model by explaining the biochemical logic of their results. Learners have less confusion, indicated by fewer discussion forum posts about challenging assessments, when we break down assessments into stepwise processes.

To give feedback to the learners on whether they answered a formative assessment correctly in real time, and provide an opportunity to reassess and adapt their strategy to answer again, every formative assessment in the MOOC has immediate grading for correctness. Moreover, since previous work demonstrates the benefit of formative feedback (Shute 2008; Bangert-Drowns and Morgan 1991; Nicol and Macfarlane-Dick 2006; Moreno 2004; Hattie and Timperley 2007), we offer detailed and specific feedback that clarifies attributes of the question target, the larger topic at hand, or the relationships between correct and incorrect responses (Shute 2008). In addition to learning more about the correct answer, or why other options are incorrect, we present the process to arrive at the correct solution through a worked example for some question types. Worked examples guide the learner step-by-step to the solution from an expert's point of view, with the intention of facilitating the transfer of knowledge and skills to similar questions (Atkinson et al. 2000).

\section{Supporting Resources}

We include a number of resources for our learners that are meant to supplement their learning, although they are not required, or count towards advancing progress (Figure 1, purple nodes). There is a separate section of the MOOC for study resources, which includes text, graphics, videos, and links that detail specific concepts, skills, and techniques that the learners should have as prerequisite knowledge. These study resources are linked explicitly in the sections of the course in which their reference could be useful. For example, in the enzyme catalysis learning sequence, we link relevant TYs to the organic chemistry study resources for a refresher on functional groups and reaction terminology. By embedding references to material that can function as a review, we are attempting to activate learner prior knowledge, which is a foundational step in facilitating lasting learning (Ambrose et al. 2010).

We also include optional molecular viewer activities. We use a molecular visualization software that structural biochemists employ in their research to help learners view and manipulate protein structural models from deposited data. Thus, these molecular viewer activities are an example of authentic learning, where learners apply their newly learned biochemistry skills in a context that is shared with professional scientists (Herrington and Kervin 2007; Herrington et al. 2004; Oliver et al. 2007; Lombardi 2007). The connection of educational materials to real-life applications is related to expert-level thinking (Semsar et al. 2011), and may help adult learners see themselves as belonging in scientific fields (Rossiter 2007). Although these activities exploring protein structure are consequential for learning, the assessments associated with them do not influence the learners' grades. Low-stakes tasks such as these facilitate trying something intellectually risky and relieve some pressure to perform on 
assessments, which may also help intrinsic motivation and self-esteem (Nicol and Macfarlane-Dick 2006). In this context, the optional molecular viewer assignments reduce the pressure to perform while engaging with a potentially unfamiliar tool.

At the bottom of each page in the course (excluding summative assessments), we include the opportunity to engage in the discussion forum. Discussion forum posts offer a way for learners to personally engage with each other and the instructors over the course material. Learners are encouraged to introduce themselves and their motivations for taking the MOOC, which we hope connects the material to personal values they hold. By articulating the value that the MOOC offers for them, learners may feel more motivated to sustain participation (Canning et al. 2018). The discussion forum is also a place where learners can have informal conversations about the material, ask for help from staff or peers, and answer each others' questions and comments. Engaging with other learners and staff, and helping each other build an understanding of course material can contribute to academic achievement and satisfaction (Kellogg, Booth, and Oliver 2014; Jung et al. 2002).

\section{Summative Assessment}

The final, summative assessment of the biochemistry MOOC is a competency exam (CE) (Figure 1, orange node). We designed the CE to test the majority of learning objectives introduced in the course by engaging in scientific thinking, synthesizing concepts, and transferring knowledge to new contexts. We use the hierarchy of cognitive processing outlined by Bloom's taxonomy (Krathwohl 2002; Krathwohl and Anderson 2009) to guide the creation of all assessments. According to the taxonomy, many CE questions require application, analysis, and evaluation, similar to PS questions. Both CE and PS questions are more cognitively demanding to answer than TYs, which require more recall.

\section{Discussion}

We used a systematic, eclectic, instructional design approach to drive our design decisions in a biochemistry MOOC. Largely this approach follows from our unique perspectives as biology $\mathrm{PhDs}$ with pedagogical experience. Our roles in course development involve learning engineering (Wilcox, Sarma, and Lippel 2016), which lays at the intersections of applying expertise in the subject matter, educational technology, instructional and graphic design, educational research, data analytics, teaching, and project management. Although familiar with the learning science literature, we are free from the constraints of specializing in a specific area of educational research set by tenure track or grants. This freedom allows us to maintain a practitioners' point of view, draw inspiration from the different frameworks of how learning works, and collectively deploy an amalgamation of strategies that enhance the design of our learning experiences.

As scientists, we value evidence-based practices, and the empirical approach the learning sciences offers. As developers of digital learning experiences, we understand that there are orchestration constraints in MOOC development that present challenges to implementing best practices for teaching and learning outlined by the literature. There is a great need to test design decisions in context, formally as randomized control trials, and more informally through the iterative revisions necessary to keep MOOCs current and rigorous. Testing in specific contexts is needed furthermore because there are differences in practice across institutions and/or courses in what best promotes engagement and learning. For example, the relationship between video 
length and learner engagement is a popular topic because of the heavy reliance on multimedia in many MOOCs. In one study, researchers recommend that videos should be less than six minutes to maximize engagement (Guo, Kim, and Rubin 2014), however, our own research indicates that video length is not a significant determinant in engagement in another one of our biology MOOCs (Thornton, Riley, and Wiltrout 2017). This exemplifies the need to test different strategies, collect learner data, and make evidence-based design decisions relevant to each course.

Application of the learning sciences to hybrid course and MOOC design provides a strong foundation of evidence-based practices that one can optimize for different online learning experiences. By documenting the process of incorporating and testing applications of the learning sciences, we can contribute to uplifting the community of practice for digital learning designers while providing a richer experience for learners.

\section{Author Contributions}

DGG and MEW contributed to the conception and scope of the perspective. DGG wrote the initial draft of the manuscript, and both authors contributed to manuscript revision, read and approved the submitted version. The authors have no potential conflicts of interest to declare.

\section{References}

Ainsworth, Shaaron, and Andrea Th Loizou. 2003. "The Effects of Self-Explaining When Learning with Text or Diagrams." Cognitive Science 27 (4): 669-81. https://doi.org/10.1207/s15516709cog2704_5.

Alario-Hoyos, Carlos, Mar Pérez-Sanagustín, Dave Cormier, and Carlos Delgado-Kloos. 2014. "Proposal for a Conceptual Framework for Educators to Describe and Design MOOCs." Journal of Universal Computer Science 20 (1): 6-23.

Alario-Hoyos, Carlos, Mar Pérez-Sanagustín, Carlos Delgado Kloos, and Pedro J. Muñoz-Merino. 2014. "Recommendations for the Design and Deployment of MOOCs: Insights about the MOOC Digital Education of the Future Deployed in MiríadaX." In Proceedings of the Second International Conference on Technological Ecosystems for Enhancing Multiculturality - TEEM '14, 403-8. Salamanca, Spain: ACM Press. https://doi.org/10.1145/2669711.2669931.

Aleven, Vincent A. W. M. M., and Kenneth R. Koedinger. 2002. "An Effective Metacognitive Strategy: Learning by Doing and Explaining with a Computer-based Cognitive Tutor." Cognitive Science 26 (2): 147-79. https://doi.org/10.1207/s15516709cog2602_1.

Ambrose, Susan A., Michael W. Bridges, Michele DiPietro, Marsha C. Lovett, and Marie K. Norman. 2010. How Learning Works: Seven Research-Based Principles for Smart Teaching. John Wiley \& Sons.

Atkinson, Robert K, Sharon J Derry, Alexander Renkl, and Donald Wortham. 2000. "Learning from Examples: Instructional Principles from the Worked Examples Research." Review of Educational Research 70 (2): 181-214.

Bangert-Drowns, Robert L, and MaryTeresa Morgan. 1991. "The Instructional Effect of Feedback in Test-like Events." Review of Educational Research 61 (2): 213-38.

Birnbaum, Monica S., Nate Kornell, Elizabeth Ligon Bjork, and Robert A. Bjork. 2013. "Why Interleaving Enhances Inductive Learning: The Roles of Discrimination and Retrieval." 
Memory \& Cognition 41 (3): 392-402. https://doi.org/10.3758/s13421-012-0272-7.

Brandl, Katharina, Stephen Schneid, and Chris Armour. 2015. "Writing on the Board versus PowerPoint: What Do Students Prefer and Why?" The FASEB Journal 29 (1_supplement): LB465. https://doi.org/10.1096/fasebj.29.1_supplement.lb465.

Bui, Dung C., and Mark A. McDaniel. 2015. "Enhancing Learning during Lecture Note-Taking Using Outlines and Illustrative Diagrams." Journal of Applied Research in Memory and Cognition 4 (2): 129-35. https://doi.org/10.1016/j.jarmac.2015.03.002.

Canning, Elizabeth A., Judith M. Harackiewicz, Stacy J. Priniski, Cameron A. Hecht, Yoi Tibbetts, and Janet S. Hyde. 2018. "Improving Performance and Retention in Introductory Biology with a Utility-Value Intervention.” Journal of Educational Psychology 110 (6): 834-49. https://doi.org/10.1037/edu0000244.

Chi, Michelene T. H., Nicholas De Leeuw, Mei-Hung Chiu, and Christian Lavancher. 1994. "Eliciting Self-Explanations Improves Understanding." Cognitive Science 18 (3): 439-77. https://doi.org/10.1207/s15516709cog1803_3.

Clark, Ruth C., and Richard E. Mayer. 2016. E-Learning and the Science of Instruction: Proven Guidelines for Consumers and Designers of Multimedia Learning. John Wiley \& Sons. Doherty, Iain, Darren Harbutt, and Neel Sharma. 2015. "Designing and Developing a MOOC." Medical Science Educator 25 (2): 177-81. https://doi.org/10.1007/s40670-015-0123-9.

Freeman, S., S. L. Eddy, M. McDonough, M. K. Smith, N. Okoroafor, H. Jordt, and M. P. Wenderoth. 2014. "Active Learning Increases Student Performance in Science, Engineering, and Mathematics." Proceedings of the National Academy of Sciences 111 (23): 8410-15. https://doi.org/10.1073/pnas.1319030111.

Guo, Philip J., Juho Kim, and Rob Rubin. 2014. "How Video Production Affects Student Engagement: An Empirical Study of MOOC Videos.” In In Proceedings of ACM Conference on Learning at Scale (L@S), 4-5.

Handelsman, J., Diane Ebert-May, Robert Beichner, Peter Bruns, Amy Chang, Robert DeHaan, Jim Gentile, et al. 2004. "EDUCATION: Scientific Teaching." Science 304 (5670): 521-22. https://doi.org/10.1126/science.1096022.

Hartley, James, and Ivor K. Davies. 1976. "Preinstructional Strategies: The Role of Pretests, Behavioral Objectives, Overviews and Advance Organizers." REVIEW OF EDUCATIONAL RESEARCH 46 (2): 28.

Hattie, John, and Helen Timperley. 2007. "The Power of Feedback." Review of Educational Research 77 (1): 81-112. https://doi.org/10.3102/003465430298487.

Herrington, Jan, and Lisa Kervin. 2007. "Authentic Learning Supported by Technology: Ten Suggestions and Cases of Integration in Classrooms." Educational Media International 44 (3): 219-36. https://doi.org/10.1080/09523980701491666.

Herrington, Jan, Thomas C. Reeves, Ron Oliver, and Younghee Woo. 2004. "Designing Authentic Activities in Web-Based Courses." Journal of Computing in Higher Education 16 (1): 3-29. https://doi.org/10.1007/BF02960280.

Honebein, Peter C., and Darryl L. Sink. 2012. "The Practice of Eclectic Instructional Design." Performance Improvement 51 (10): 26-31. https://doi.org/10.1002/pfi.21312.

Jung, Insung, Seonghee Choi, Cheolil Lim, and Junghoon Leem. 2002. "Effects of Different Types of Interaction on Learning Achievement, Satisfaction and Participation in Web-Based Instruction." Innovations in Education and Teaching International 39 (2): 153-62. https://doi.org/10.1080/14703290252934603. 
Karpicke, Jeffrey D., and Henry L. Roediger. 2007. "Expanding Retrieval Practice Promotes Short-Term Retention, but Equally Spaced Retrieval Enhances Long-Term Retention." Journal of Experimental Psychology: Learning, Memory, and Cognition 33 (4): 704-19. https://doi.org/10.1037/0278-7393.33.4.704.

Kellogg, Shaun, Sherry Booth, and Kevin Oliver. 2014. "A Social Network Perspective on Peer Supported Learning in MOOCs for Educators." The International Review of Research in Open and Distributed Learning 15 (5). https://doi.org/10.19173/irrodl.v15i5.1852.

Kopp, Michael, and Elke Lackner. 2014. "DO MOOCS NEED A SPECIAL INSTRUCTIONAL DESIGN?" Proceedings of EDULEARN14 Conference, July, 11.

Krathwohl, David R. 2002. “A Revision of Bloom's Taxonomy: An Overview." Theory Into Practice 41 (4): 212-18. https://doi.org/10.1207/s15430421tip4104_2.

Krathwohl, David R., and Lorin W. Anderson. 2009. A Taxonomy for Learning, Teaching, and Assessing: A Revision of Bloom's Taxonomy of Educational Objectives. Longman.

Lee, Gayoung, Sunyoung Keum, Myungsun Kim, and Yoomi Choi. 2016. "A Study on the Development of a MOOC Design Model.” Educational Technology International 17 (1): $1-37$.

Lombardi, Marilyn M. 2007. "Authentic Learning for the 21st Century: An Overview." Educause Learning Initiative 1: 1-12.

Mayer, Richard E. 2017. "Using Multimedia for E-Learning: Multimedia for e-Learning." Journal of Computer Assisted Learning 33 (5): 403-23. https://doi.org/10.1111/jcal.12197.

Mayer, Richard E., Amanda Mathias, and Karen Wetzell. 2002. "Fostering Understanding of Multimedia Messages through Pre-Training: Evidence for a Two-Stage Theory of Mental Model Construction." Journal of Experimental Psychology: Applied 8 (3): 147-54. http://dx.doi.org/10.1037/1076-898X.8.3.147.

Meng, Karen, and Del Patty. 1991. "Field Dependence and Contextual Organizers." The Journal of Educational Research 84 (3): 183-89.

Miyatsu, Toshiya, Khuyen Nguyen, and Mark A. McDaniel. 2018. "Five Popular Study Strategies: Their Pitfalls and Optimal Implementations." Perspectives on Psychological Science 13 (3): 390-407. https://doi.org/10.1177/1745691617710510.

Moreno, Roxana. 2004. "Decreasing Cognitive Load for Novice Students: Effects of Explanatory versus Corrective Feedback in Discovery-Based Multimedia." Instructional Science 32 (1/2): 99-113. https://doi.org/10.1023/B:TRUC.0000021811.66966.1d.

Mott, Bradford W, Charles B Callaway, Luke S Zettlemoyer, Seung Y Lee, and James C Lester. 1999. "Towards Narrative-Centered Learning Environments." Proceedings of the 1999 AAAI Fall Symposium on Narrative Intelligence, 78-82.

Nicol, David J., and Debra Macfarlane-Dick. 2006. "Formative Assessment and Self-regulated Learning: A Model and Seven Principles of Good Feedback Practice." Studies in Higher Education 31 (2): 199-218. https://doi.org/10.1080/03075070600572090.

Oliver, Ron, Anthony Herrington, Jan Herrington, and Thomas C. Reeves. 2007. "Representing Authentic Learning Designs Supporting the Development of Online Communities of Learners.” Journal of Learning Design 2 (2): 1-21. https://doi.org/10.5204/jld.v2i2.36.

Paivio, Allan, Mary Walsh, and Trudy Bons. 1994. "Concreteness Effects on Memory: When and Why?" Journal of Experimental Psychology: Learning, Memory, and Cognition 20 (5): 1196-1204. 
Peterson, Christine. 2003. "Bringing ADDIE to Life: Instructional Design at Its Best." Journal of Educational Multimedia and Hypermedia 12 (3): 227-41.

Reiser, Brian J. 2004. "Scaffolding Complex Learning: The Mechanisms of Structuring and Problematizing Student Work." Journal of the Learning Sciences 13 (3): 273-304. https://doi.org/10.1207/s15327809j1s1303_2.

Roediger, Henry L., and Andrew C. Butler. 2011. "The Critical Role of Retrieval Practice in Long-Term Retention.” Trends in Cognitive Sciences 15 (1): 20-27. https://doi.org/10.1016/j.tics.2010.09.003.

Roediger, Henry L., and Jeffrey D. Karpicke. 2006. "The Power of Testing Memory: Basic Research and Implications for Educational Practice." Perspectives on Psychological Science 1 (3): 181-210. https://doi.org/10.1111/j.1745-6916.2006.00012.x.

Rossiter, Marsha. 2007. "Possible Selves: An Adult Education Perspective." New Directions for Adult \& Continuing Education, no. 114 (Summer): 5-15. https://doi.org/10.1002/ace.252.

Rowland, Christopher A. 2014. "The Effect of Testing versus Restudy on Retention: A Meta-Analytic Review of the Testing Effect." Psychological Bulletin 140 (6): 1432-63. https://doi.org/10.1037/a0037559.

Semsar, Katharine, Jennifer K. Knight, Gülnur Birol, and Michelle K. Smith. 2011. "The Colorado Learning Attitudes about Science Survey (CLASS) for Use in Biology." Edited by Diane K. O’Dowd. CBE_Life Sciences Education 10 (3): 268-78. https://doi.org/10.1187/cbe.10-10-0133.

Shah, Dhawal. 2019. “Class Central's Top 100 MOOCs of All Time (2019 Edition)." Class Central. August 19, 2019. https://www.classcentral.com/report/top-moocs-2019-edition/.

Shute, Valerie J. 2008. "Focus on Formative Feedback." Review of Educational Research 78 (1): 153-89. https://doi.org/10.3102/0034654307313795.

Sweller, John. 1994. "Cognitive Load Theory, Learning Difficulty, and Instructional Design." Learning and Instruction 4 (4): 295-312. https://doi.org/10.1016/0959-4752(94)90003-5. . 2005. "Implications of Cognitive Load Theory for Multimedia Learning." In The Cambridge Handbook of Multimedia Learning, 19-30. New York, NY, US: Cambridge University Press. https://doi.org/10.1017/CBO9780511816819.003.

Sweller, John, Jeroen J. G. van Merriënboer, and Fred Paas. 2019. "Cognitive Architecture and Instructional Design: 20 Years Later.” Educational Psychology Review 31 (2): 261-92. https://doi.org/10.1007/s10648-019-09465-5.

Thornton, Sera, Ceri Riley, and Mary Ellen Wiltrout. 2017. "Criteria for Video Engagement in a Biology MOOC.” In Proceedings of the Fourth (2017) ACM Conference on Learning@ Scale-L@S'17, 291-94. Cambridge, Massachusetts, USA: ACM Press. https://doi.org/10.1145/3051457.3054007.

Veletsianos, George, and Peter Shepherdson. 2016. "A Systematic Analysis and Synthesis of the Empirical MOOC Literature Published in 2013-2015." The International Review of Research in Open and Distributed Learning 17 (2). https://doi.org/10.19173/irrodl.v17i2.2448.

Weinstein, Yana, Christopher R. Madan, and Megan A. Sumeracki. 2018. "Teaching the Science of Learning." Cognitive Research: Principles and Implications 3 (1): 2. https://doi.org/10.1186/s41235-017-0087-y.

Weisberg, Joseph S. 1970. "The Use of Visual Advance Organizers for Learning Earth Science Concepts.” Journal of Research in Science Teaching 7 (2): 161-65. 
https://doi.org/10.1002/tea.3660070212.

Wilcox, Karen E., Sanjay Sarma, and Philip H. Lippel. 2016. "Online Education: A Catalyst for Higher Education Reforms.” MIT Online Education Policy Initiative. Massachusetts Institute of Technology.

Wylie, Ruth, and Michelene T H Chi. 2014. "The Self-Explanation Principle in Multimedia Learning." In The Cambridge Handbook of Multimedia Learning, 2nd Edition, 413-32. New York, NY: Cambridge University Press.

Yanchar, Stephen C., and Bruce W. Gabbitas. 2011. "Between Eclecticism and Orthodoxy in Instructional Design." Educational Technology Research and Development 59 (3): 383-98. https://doi.org/10.1007/s11423-010-9180-3.

Yousef, Ahmed Mohamed Fahmy, Mohamed Amine Chatti, Ulrik Schroeder, and Marold Wosnitza. 2014. "What Drives a Successful MOOC? An Empirical Examination of Criteria to Assure Design Quality of MOOCs." In 2014 IEEE 14th International Conference on Advanced Learning Technologies, 44-48. Athens, Greece: IEEE. https://doi.org/10.1109/ICALT.2014.23.

Supplementary Figure 1. An example of an image handout from the protein structure learning sequence highlighting essential images complete with focused, open-ended concept questions.

Supplementary Video 1. A clip of a video segment detailing the steps in calcium ion transportation, where we cut back and forth between the professor explaining each step to a live classroom and an animation of this dynamic process added in post-production. 